\title{
The Impact of Police Work-Family Conflict on Turnover Intentions: The Roles of Organizational Support and Job Burnout
}

\author{
Jianglin Ke, Jialin Zhou*, Wenhua Zhu \\ Beijing Normal University, Beijing, China \\ Email: *bnujlzhou@163.com
}

How to cite this paper: Ke, J.L., Zhou, J.L. and Zhu, W.H. (2019) The Impact of Police Work-Family Conflict on Turnover Intentions: The Roles of Organizational Support and Job Burnout. Open Journal of Social Sciences, 7, 1-12.

https://doi.org/10.4236/jss.2019.74001

Received: March 7, 2019

Accepted: April 5, 2019

Published: April 8, 2019

Copyright ( 2019 by author(s) and Scientific Research Publishing Inc. This work is licensed under the Creative Commons Attribution International License (CC BY 4.0).

http://creativecommons.org/licenses/by/4.0/

\section{Open Access}

\begin{abstract}
Work-family conflict is always considered to have a positive influence on job burnout and turnover intentions. But things may be different for Chinese police, who may be less likely to leave their job because of their firm beliefs and higher welfare. Considering this, we use Beijing police as the sample of our research, and explore the impact of work-family conflict on turnover intentions under the roles of organizational support and job burnout. By analyzing 316 valid questionnaires surveyed from the Beijing public security system, we get the following conclusions: work-family conflict and job burnout have a significant and positive correlation with turnover intentions; job burnout plays a partial mediating role in the relationship between work-family conflict and turnover intentions; organizational support plays a moderating role between work-family conflict and job burnout.
\end{abstract}

\section{Keywords}

Work-Family Conflict, Turnover Intentions, Organizational Support, Job Burnout

\section{Introduction}

Nowadays, more and more phenomena, such as police's death from overwork, the increasing tendency of police's divorce rates and so on, remind us to pay attention to the effect of organizational support on police's job burnout and work-family conflict. The concept of work-family conflict is first proposed by Kahn et al. [1]. They thought individuals play different roles in work and family. The conflicts between work and family are caused by the needs of different characters. Aryee et al. put forward an important point of view that work-family conflict has two dimensions [2]. The interference of family-related responsibility 
due to working time, stress and other factors is the conflict between work and family (work-to-family conflict); family-to-work conflict due to family-related responsibility. Police is a special profession, which is rarely studied. They have not only stressful and high-risk work, but also unstable working time. These work characteristics will have many impacts on fulfilling obligations as a family member. Therefore, this paper focuses on the work's influence on family of the police, which explores the relationship between work-family conflict, organizational support, job burnout, and turnover intentions. We try to make suggestions based on the research results. Our general hypothesized model is depicted in Figure 1.

\subsection{Work-Family Conflict and Job Burnout}

Job Burnout refers to a long-term stress response of an individual to the ongoing emotional and interpersonal stressors at work, including exhaustion, cynicism, and inefficacy [3]. There are many factors that cause job burnout, and the work-family conflict is one of them. Bacharach, Bamberger, \& Conley's studies of nurses and engineers confirm that job burnout is an important direct consequence variable of work-family conflict [4]. Li et al. concluded that work-family conflict and job burnout's three dimensions are significantly related by using medical staff as research samples [5]. Based on the above, we can have the following hypothesis:

Hypothesis 1: Work-family conflict will positively relate to job burnout.

\subsection{Work-Family Conflict and Turnover Intentions}

Turnover intentions refer to a psychological tendency of employees who want to transfer away from existing organizations or jobs [6]. Work and family are two important aspects for people. When there are conflicts between them, one of them have to make concessions. If one regards family as a more important thing, he/she may care less about work and have turnover intentions. Elloy and Smith believe that work's influence on the family is a key predictor of individual turnover intentions [7]. Because leaving from work can eliminate work-to-family interference and reduce work-family conflict. Zheng, Chen, and Zheng found the positive impact of work-family conflict and turnover intentions through researches on

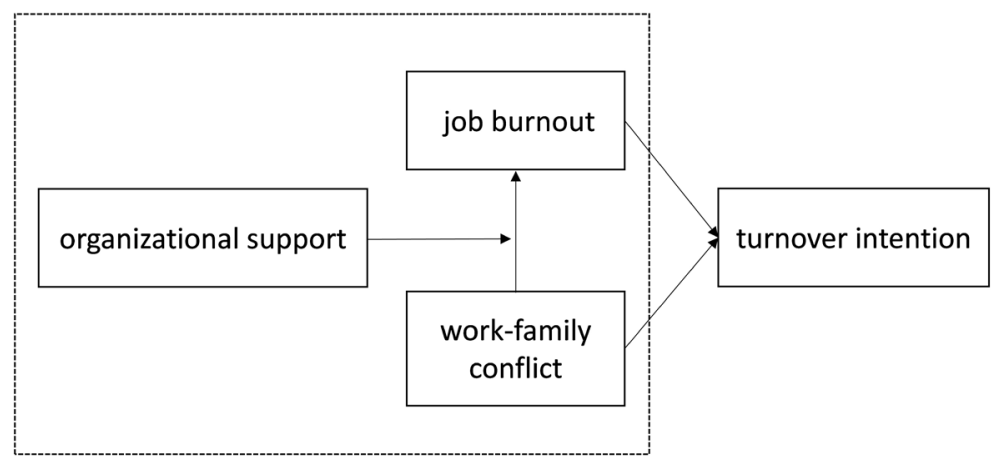

Figure 1. Hypothesized model. 
R\&D personnel [8]. Chen, Tian, and Wang have reached similar conclusions by studying employees of different companies [6]. Based on the above, we can have the following hypothesis:

Hypothesis 2: Work-family conflict will positively relate to turnover intentions.

\subsection{Job Burnout and Turnover Intentions}

Many scholars are interested in the relationship between job burnout and turnover intentions. If one is tired about working, it's hard to know if he/she will stay in the same organizations and continue working. When job burnout occurs, employees feel physical and psychological exhaustion. In the absence of relief, there are more likely to be a turnover intention [9]. Li, Gao, and Shen have studied the relationship between teacher's burnout and turnover intentions, which confirms some dimensions of job burnout, such as exhaustion and cynicism, are significantly and positively correlated with turnover intentions [10]. Zhao, and Li found that job burnout has a positive predictive effect on turnover intentions through the study on knowledge workers after the 1980s [11]. Xue et al. also mentioned in the study that for doctors in public hospitals, the three dimensions of job burnout are all related to turnover intentions [12]. Based on the above, we can have the following hypothesis:

Hypothesis 3: Job burnout will positively relate to turnover intentions.

\subsection{The Role of Job Burnout}

There are lots of studies on the mediating role of job burnout between turnover intentions and other variables. Huang, Chuang, and Lin thought that job burnout's two sub-dimensions, exhaustion and cynicism, mediate between organizational politics and turnover intentions perceived by employees [13]. In the above literature review, work-family conflict is found to have a significant and positive correlation between job burnout and turnover intentions; there is also a significant and positive correlation between work-family conflict and job burnout. The long-term stress response can be used as a result variable of work-family conflict and an antecedent of turnover intentions. Based on the above, we can have the following hypothesis:

Hypothesis 4: Job burnout will mediate the effect of work-family conflict on turnover intentions.

\subsection{The Role of Organizational Support}

American social psychologist Eisenberger proposed the concept of perceived organizational support based on organization support theory [14]. Turnover intentions represent a significant cognitive shift for employees as they begin to detach from the organization [15]. Based on the social exchange theory [16], organizational support may increase the investment outside the employee's role, resulting in a sense of return obligation [17]. Many studies prove that organiza- 
tional support can have a positive impact on employees and organizations.

Researchers have done a lot of work on the relationship between work-family conflict, organizational support and job burnout. Moore pointed out in the study that organizational support, especially superior support, has a significant effect on reducing job burnout [18]. Allen, Herst, \& Bruek found that the higher the organizational support of employees is, the lower turnover intentions are [19]. And the sense of organizational support can alleviate turnover intentions of employees. Based on the above, we can have the following hypothesis:

Hypothesis 5: Organizational support will moderate the relationship between work-family conflict and job burnout.

\section{Method}

Sample Description. The survey was conducted on the police in Beijing, and a total of 321 questionnaires were collected mainly through WeChat in the form of electronic questionnaires. Among them, there are 316 valid questionnaires. The basic information of respondents can be seen from Table 1.

In Table 1, number of children shows how many children are there in the family. Number of old people means how many old people are there in the family of respondents. Length of work measures how long the respondents have been police. Family economic situation indicates current economic status of the respondents' family.

Research Design. We mainly conduct quantitative research and use the SPSS 20.0 and Amos as tools to analyze. In the design of the questionnaire, in addition to the demographic variables, we use the Likert five-level scale to evaluate respondents' evaluation of each variable. Then we test hypotheses and draw conclusions through the analysis of reliability, validity, correlation, regression, etc.

\section{Measures.}

Work-Family Conflict. The work-family conflict scale is mainly from the scale built by Carlson, Kacmar, \& Williams, which includes work-family conflicts and family-work conflicts. It is a two-way study from three dimensions of time conflicts, stress conflicts and behavior conflicts [20]. The focus of our study is work-to-family interference. That is, because of the involvement of work roles, family life has been affected. So we only refer to its work-family conflict scale. The scale has three dimensions. Respondents used a 5-point Likert scale $(1=$ strongly disagree to 5 = strongly agree).

Job Burnout. The measurement of Beijing police's job burnout is mainly based on the review of the burnout questionnaire revised by Li et al. [5]. They developed a set of scales in line with China's national conditions based on Maslach Burnout Inventory [21]. The questionnaire has 22 items and three dimensions, which are exhaustion, emotional alienation and personal accomplishment. Respondents used a 5 -point Likert scale ( $1=$ strongly disagree to $5=$ strongly agree).

Turnover Intentions. The scale we used for the measurement of Beijing police turnover intentions mainly refers to Mobley, Horner, and Hollingsworth's 
Table 1. Respondents' basic information.

\begin{tabular}{|c|c|c|c|}
\hline Item & Category & Number of respondent & Percentage (\%) \\
\hline \multirow{2}{*}{ Gender } & $0=$ Male & 228 & 72.15 \\
\hline & $1=$ Female & 88 & 27.85 \\
\hline \multirow{4}{*}{ Age } & $1=\leq 25$ & 12 & 3.8 \\
\hline & $2=26-35$ & 224 & 70.89 \\
\hline & $3=36-45$ & 48 & 15.19 \\
\hline & $4=>45$ & 32 & 10.13 \\
\hline \multirow{2}{*}{ Marital status } & $1=$ Married & 232 & 73.42 \\
\hline & $2=$ Single & 84 & 26.58 \\
\hline \multirow{3}{*}{ Number of children } & 0 & 136 & 43.04 \\
\hline & 1 & 168 & 53.16 \\
\hline & $\geq 2$ & 12 & 3.8 \\
\hline \multirow{5}{*}{ Number of old people } & 0 & 76 & 24.05 \\
\hline & 1 & 16 & 5.06 \\
\hline & 2 & 88 & 27.85 \\
\hline & 3 & 24 & 7.59 \\
\hline & 4 & 112 & 35.44 \\
\hline \multirow{4}{*}{ Education level } & $1=$ beyond college degree & 0 & 0 \\
\hline & $2=$ college degree & 28 & 8.86 \\
\hline & $3=$ bachelor degree & 220 & 69.62 \\
\hline & $4=$ master & 68 & 21.52 \\
\hline \multirow{4}{*}{ Length of work } & $1=0-2$ years & 12 & 3.8 \\
\hline & $2=3-5$ years & 64 & 20.25 \\
\hline & $3=5-10$ years & 172 & 54.43 \\
\hline & $4=11$ years or more & 68 & 21.52 \\
\hline \multirow{4}{*}{$\begin{array}{l}\text { Average weekly } \\
\text { working hours }\end{array}$} & $1=40$ hours & 20 & 6.33 \\
\hline & $2=40-60$ hours & 136 & 43.04 \\
\hline & $3=60-80$ hours & 116 & 36.71 \\
\hline & $4=80-100$ hours & 44 & 13.92 \\
\hline \multirow{5}{*}{$\begin{array}{l}\text { Family economic } \\
\text { situation }\end{array}$} & $1=$ live in poverty & 0 & 0 \\
\hline & $2=$ poor living conditions & 28 & 8.86 \\
\hline & $\begin{array}{c}3=\text { Life is comfortable, but } \\
\text { no extra savings. }\end{array}$ & 220 & 69.62 \\
\hline & $\begin{array}{l}4=\text { Life is very comfortable, } \\
\text { and there are some savings }\end{array}$ & 68 & 21.52 \\
\hline & $\begin{array}{c}5=\text { have never worried } \\
\text { about money }\end{array}$ & 12 & 3.8 \\
\hline
\end{tabular}


scale, which has four questions [22]. Respondents used a 5-point Likert scale (1 $=$ strongly disagree to 5 = strongly agree).

Organization Support. The measurement of organizational support mainly refers to the scale compiled by Eisenberger, \& Adornetto [23]. The description of a few topics has been modified to make it more suitable for our research. The scale has three dimensions: the organization's value recognition to employees, work support, and interest. There are 6 questions in the scale. Respondents used a 5 -point Likert scale ( $1=$ strongly disagree to $5=$ strongly agree $)$.

Control Variables. Participants indicated their gender $(0=$ male, $1=$ female $)$, age $(1=\leq 25,2=26-35,3=36-45,4=>45)$, marital status $(1=$ married, $2=$ single), number of children, number of old people, educational level (ranging from 1 = beyond college degree to $4=$ master $)$, length of work $(1=0-2$ years, 2 $=3-5$ years, $3=5-10$ years, $4=11$ years or more), average weekly working hours ( $1=40$ hours, $2=40-60$ hours, $3=60-80$ hours, $4=80-100$ hours $)$, and family economic situation (with 5 categories ranging from $1=$ live in poverty to 5 = have never worried about money). We measured these variables because demographic characteristics may have an impact on results [24]. The differences in Age, gender, marital status and education level will affect a person's perception of things. Family situation (number of children, number of old people, and economic situation) and work situation (length of work and average weekly working hours) may have an influence on work conditions and satisfaction.

\section{Results}

Confirmatory Factor Analysis. We followed the approach suggested by Vandenberg and Lance, and conducted confirmatory factor analysis, which is used to investigate the discriminant validity between the study variables [25]. The fitting indices of the model are TLI $=0.904, \mathrm{CFI}=0.943$, and RMSEA $=0.077$. The fitting indicators reached the standards recognized by the academic community, which means the four variables involved have well discriminant validity.

Descriptive statistics, correlations, and internal consistency reliabilities (coefficient alphas) are provided in Table 2. It can be seen that all the Cronbach's $\alpha$ coefficients are between 0.850 - 0.930, and the "deleted $\alpha$ coefficient" is smaller than the $\alpha$ coefficient, indicating that the questionnaire is in high reliability.

Test of Hypotheses. Hypothesis 1, 2 and 3 are all about correlation. Correlation analysis was used to analyze the relationship among work-family conflict,

Table 2. Descriptive statistics and correlation analysis of variables.

\begin{tabular}{lcccccc}
\hline \multicolumn{1}{c}{ Viriable } & M & SD & 1 & 2 & 3 & 4 \\
\hline 1. Work-family conflict & 4.072 & 0.754 & $(0.929)$ & & & \\
2. Job burnout & 3.246 & 0.705 & $0.554^{\star *}$ & $(0.907)$ & & \\
3. Turnover intentions & 2.97 & 1.125 & $0.160^{\star *}$ & $0.538^{\star *}$ & $(0.890)$ & \\
4. Organizational support & 2.772 & 0.798 & $-0.112^{\star}$ & $-0.184^{\star *}$ & $-0.251^{\star *}$ & $(0.895)$ \\
\hline
\end{tabular}

Note: $\mathrm{N}=316,{ }^{* *} \mathrm{P}<0.01$. Coefficient alphas is in brackets. 
job burnout, turnover intentions, and organizational support. We mainly used Pearson coefficient for the correlation coefficient test. Positive values indicate positive correlation, while negative values indicate negative correlation. Table 2 shows the results.

From the analysis results in Table 2, work-family conflict is significantly and positively correlated with job burnout, which supports hypothesis 1 . We also found a significant and positive correlation between work-family conflict and turnover intentions. Though the correlation coefficient is low, hypothesis 2 is supported; Job burnout and work-family conflict have significant and positive correlation, which confirms hypothesis 3.

To test hypothesis 4 , we mainly use regression analysis to ensure whether job burnout plays a mediating role between work-family conflict and turnover intentions. Under the control of gender, age and other control variables, the results of multiple analysis are shown in Table 3.

It can be seen from Table 3 that gender has a significant and positive effect on turnover intentions. Gender influences turnover intentions significantly and positively. Age, number of old people, educational level and family economic situation have significant and negative effects on turnover intentions, which means if the police are older, poorer and have more old people to care, they will have less turnover intentions.

Work-family conflict has a significant effect on the turnover intentions $(\beta=$ $0.232, \mathrm{p}<0.01)$ and job burnout $(\beta=0.479, \mathrm{p}<0.01)$. Job burnout has a significant effect on turnover intentions $(\beta=0.919, \mathrm{p}<0.01)$. After the introduction of

Table 3. Analysis of the mediating role of job burnout.

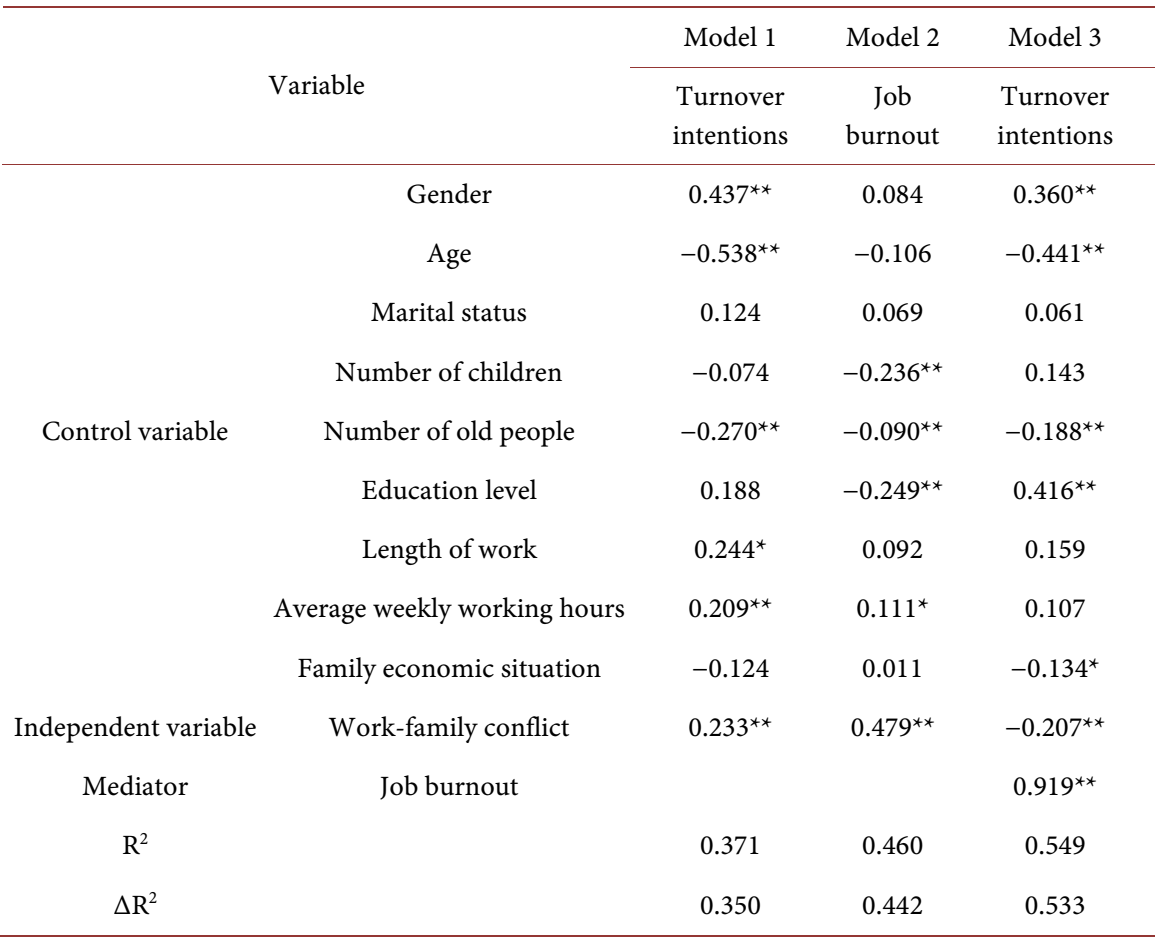

Note. $\mathrm{N}=316,{ }^{* *} \mathrm{p}<0.01,{ }^{*} \mathrm{p}<0.05$. 
mediator job burnout, the effect of work-family conflict on turnover intentions remained significant $(\beta=-0.207, \mathrm{p}<0.01)$, and the effect reduced comparing with model 1 , which shows that job burnout plays a partial mediating role in the relationship between work-family conflict and turnover intentions. Therefore, hypothesis 4 is supported.

As for hypothesis 5, in order to test the role of organizational support in moderating the relationship between work-family conflict and job burnout, we use hierarchical regression analysis. The results of the analysis are shown in Table 4.

The results show that both work-family conflict and organizational support have significant predictive effects on job burnout. Organizational support positively moderates the relationship between work-family conflict and job burnout ( $B=0.168, p<0.01$ ), which supports hypothesis 5 . Thus, an adjustment effect map can be drawn (Figure 2). As can be seen from Figure 2, when organizational support is low, the positive effect of work-family conflicts on job burnout is stronger; when organizational support is high, the positive effect of work-family conflict on job burnout is weaker.

\section{Conclusions}

Our study not only found a significant moderation effect of organization support on the relationship between work-family conflict and job burnout, but also

Table 4. The role of organizational support in moderating the relationship between work-family conflict and job burnout.

\begin{tabular}{|c|c|c|c|c|c|}
\hline & \multirow{2}{*}{ Variable } & \multicolumn{4}{|c|}{ Job burnout } \\
\hline & & Model 1 & Model 2 & Model 3 & Model 4 \\
\hline & Gender & 0.125 & 0.084 & 0.118 & 0.114 \\
\hline & Age & -0.147 & -0.106 & -0.120 & $-0.122^{\star *}$ \\
\hline & Marital status & 0.088 & 0.069 & 0.070 & 0.077 \\
\hline & Number of children & -0.181 & $-0.236^{* *}$ & $0.218^{* *}$ & $-0.206^{* *}$ \\
\hline \multirow[t]{5}{*}{ Control variable } & Number of old people & $-0.096^{\star *}$ & $-0.090^{* *}$ & $-0.095^{\star *}$ & $-0.094^{\star *}$ \\
\hline & Education level & $-0.338^{\star *}$ & $-0.249^{* *}$ & $-0.263^{\star *}$ & $0.314^{* *}$ \\
\hline & Length of work & $0.180^{*}$ & 0.092 & 0.111 & 0.118 \\
\hline & Average weekly working hours & $0.220^{* *}$ & $0.111^{\star}$ & $0.094^{*}$ & 0.081 \\
\hline & Family economic situation & -0.059 & 0.011 & -0.023 & 0.037 \\
\hline \multirow[t]{2}{*}{ Direct effect } & Work-family conflict (a) & & $0.479^{\star *}$ & $0.467^{\star *}$ & $0.469^{* *}$ \\
\hline & Organizational support (b) & & & $-0.092^{*}$ & $-0.130^{* *}$ \\
\hline Indirect effect & $\mathrm{a} \times \mathrm{b}$ path & & & & $0.168^{* *}$ \\
\hline $\mathrm{R}^{2}$ & & 0.238 & 0.460 & 0.469 & 0.489 \\
\hline$\Delta \mathrm{R}^{2}$ & & 0.216 & 0.442 & 0.450 & 0.469 \\
\hline $\mathrm{F}$ & & $10.631^{* *}$ & $25.982^{\star *}$ & $24.456^{* *}$ & $24.158^{\star *}$ \\
\hline
\end{tabular}

Note. $N=316,{ }^{*} p<0.01,{ }^{*} p<0.05$. 


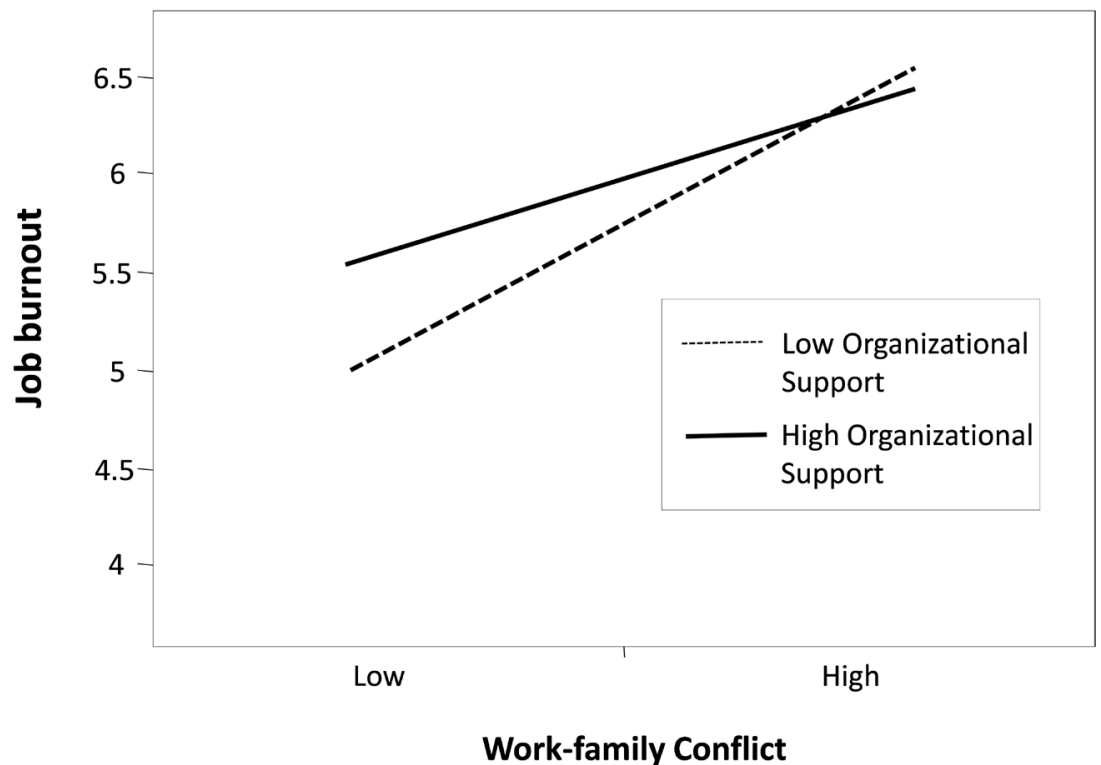

Figure 2. The role of organizational support on the moderating effect of work-family conflicts and job burnout.

found a mediation effect of job burnout on the relationship between work-family conflict and turnover intentions. Up to now, many researchers have studied work-family conflict through different professional practitioners, including medical staff [3] [12], research and development personnel [5], teachers [10], and company employee [26] [11], but the relevant research on police is still in its infancy. We collect data from Beijing police and discuss the role of organizational support and job burnout in the relationship between work-family conflict and turnover intentions, enriching theories on work-family conflict and helping people understand the internal mechanisms of work-family conflicts better.

Here are our main findings. First, the empirical conclusions of the study support the theoretical assumptions of positive correlation among work-family conflict, job burnout, and turnover intentions. This is similar to the conclusions of Frone, Russell, \& Cooper [27], Zheng, Zheng, \& Chen [8], and Xue, et al. [12]. That is, the increase of work-family conflict may lead to an increase in job burnout, and may also lead individuals to be more inclined to leave their jobs. Second, our study finds that organizational support moderates the relationship between work-family conflict and job burnout. When organizational support is low, work-family conflict has a strong and positive effect on job burnout; when organizational support is high, the positive effect of work-family conflict on job burnout is weaker. This is consistent with the findings of Allen, Herst, \& Bruek [19]. On this basis, Maslach further pointed out that the support of the superiors is more effective in eliminating job burnout than the support from colleagues [3]. Third, the results show that job burnout plays a mediating role in the relationship between work-family conflict and turnover intentions, which is similar to Xue et al.'s [12] and Liang's [9] conclusion. But the research samples are different and multiple. Therefore, turnover intentions caused by job burnout may 
be common for people working in organizations.

\section{Discussion}

Our findings offer several important implications for research and practice. First, organizations must be aware of the significant and positive correlation between work-family conflict, job burnout and turnover intentions. If organizations can alert scientifically and help the police balance work and family, they can motivate the police to work, reduce their tendency to leave, and maintain the unity of the police community and high morale. Second, our research provides a new problem-solving perspective for organizations that want to improve the negative working conditions. For the police, they have large workload, heavy task and dangerous work. When the pay and return are not equal, it is more likely to cause job burnout. Therefore, the public security departments and relevant departments should pay more attention to providing organizational support, enhance their sense of organizational support, and maintain their enthusiasm for work. Third, our findings provide a new perspective for solving the negative effect of work-family conflict on turnover intentions. In order to keep the stability of the police and reduce turnover intentions, organizations can use relevant measures to balance work-family conflict, like providing flexible working hours and more convenience to their relatives and children. Besides, it can also be achieved through direct intervention in job burnout to reduce the negative impact of work-family conflict on turnover intentions, such as more social support, work enrichment, transformational leadership styles and so on [28]. At the same time, public security units should also strengthen political theory learning, cultivate the professional ethics and moral quality of the police, and guide them to create value recognition for the police, which can also reduce their job burn to a certain extent.

In summary, after controlling demographic variables, our study found the relationship between police work family conflict, job burnout, turnover intentions and organizational support, and provided new ideas for the intervention of police turnover and job burnout.

\section{Limitations and Future Directions for Research}

There are several limitations in our study. First, our data are from a single source. There are many different kinds of police, such as traffic police, swat, and so on. Their work is different, and they belong to different departments. We didn't make a detailed division on the samples, so it may influence the results. Nevertheless, future researches could expand the size of samples and divide the samples according to work units. Second, we only focus on the influence that work may have on the family because of the special characteristics of police. However, family-related responsibilities may also cause work-family conflict [2] [6]. Therefore, future researches could take the two-way nature of conflicts between work and family into consideration. Third, data remain static and cannot 
reflect changes. We use only a few days to collect data. So our study is static and horizontal. But with the change of relevant policies and the reform of the public security system, some variables may change. Therefore, to give a more exhaustive research, taking time-lagged design into consideration while collecting data is a good way to combine dynamic and static state [24].

\section{Conflicts of Interest}

The authors declare no conflicts of interest regarding the publication of this paper.

\section{References}

[1] Kahn, R.L., Wolfe, D.M., Quinn, R., Snoek, J.D. and Rosenthal, R.A. (1964) Organizational Stress. Wiley, New York.

[2] Aryee, S., Luk, V., Leung, A., et al. (1999) Role Stressors, Interrole Conflict, and Well-Being: The Moderating Influence of Spousal Support and Coping Behaviors among Employed Parents in Hong Kong. Journal of Vocational Behavior, 54, 259-278. https://doi.org/10.1006/jvbe.1998.1667

[3] Maslach, C., Schaufeli, W.B. and Leiter, M.P. (2001) Job Burnout. Annual Review of Psychology, 52, 397-422. https://doi.org/10.1146/annurev.psych.52.1.397

[4] Bacharach, S.B., Bamberger, P. and Conley, S. (1991) Work-Home Conflict among Nurses and Engineers: Mediating the Impact of Role Stress on Burnout and Satisfaction at Work. Journal of Organizational Behavior, 12, 39-53. https://doi.org/10.1002/job.4030120104

[5] Li, C.P., Shi, K., Luo, Z.X., Yang, Y. and Li, L. (2003) The Relationship between Work-Family Conflict and Job Burnout of Medical Staff. Chinese Journal of Mental Health, 12, 807-809.

[6] Chen, Z.W., Tian, S.Q. and Wang, J.L. (2014) Research on the Relationship between the Two-Way Work-Family Conflict and Turnover Intention. Soft Science, 28, 65-69.

[7] Elloy, D.F. and Smith, C.R. (2003) Patterns of Stress, Work-Family Conflict, Role Conflict, Role Ambiguity and Overload among Dual-Career and Single Career Couples: An Australian Study. Cross Cultural Management, 1, 55-66. https://doi.org/10.1108/13527600310797531

[8] Zheng, X.S., Zheng, X.T. and Chen, L.F. (2006) Research on the Impact of Work-Family Conflicts on the Work Attitude of R\&D Staff. Science Research, 2, 540-545.

[9] Liang, Q.Q. (2018) Empirical Study on Factors of Knowledge Workers' Turnover Intention: From the Perspective of Career Development Stage and Job Burnout. Technical, Economic and Management Research, 1, 58-62.

[10] Li, Y.X., Gao, D.D. and Shen, J.L. (2007) Teacher Burnout and Self-Esteem Relationship between Mental Health and Turnover Intention. Psychological Development and Education, 4, 83-87.

[11] Zhao, Y.S. and Li, M. (2012) Research on the Relationship between Job Burnout and Turnover Intention of Knowledge-Based Employees in Enterprises after 80-Based on the Supporting Sense of Organizational Support. Shanghai Management Science, 3, 75-79.

[12] Xue, Z.H., Yin, W.Q., Huang, D.M., Meng, H.W., Ren, G.F., Chen, Z.M. and Wang, 
F. (2012) Research on the Relationship between Doctors' Occupational Exhaustion and Turnover Intention in Public Hospitals. Journal of Health Science and Technology, 5, 477-479.

[13] Huang, I., Chuang, C. and Lin, H. (2003) The Role of Burnout in the Relationship between Perceptions of Organizational Politics and Turnover Intentions. Public Personnel Management, 32, 519-532.

[14] Eisenberger, R., Huntington, R., Hutchison, S., et al. (1986) Perceived Organizational Support. Journal of Applied Psychology, 71, 500-507. https://doi.org/10.1037/0021-9010.71.3.500

[15] Burris, E.R., Detert, J.R. and Chiaburu, D.S. (2008) Quitting before Leaving: The Mediating Effects of Psychological Attachment and Detachment on Voice. Journal of Applied Psychology, 93, 912-922. https://doi.org/10.1037/0021-9010.93.4.912

[16] Homans, G.C. (1967) The Nature of Social Exchange.

[17] Sun, J.M., Jiao, H.T. and Zhao, J. (2011) The Moderating Effect of Perceived Organizational Support in Job Engagement And Work-Family Conflicts. Chinese Journal of Applied Psychology, 17, 31-35.

[18] Moore, J.E. (2002) Why Is This Happening? A Casual Attribution Approach to Work Exhaustion Consequence. Academy of Management Review, 2, 18-22.

[19] Allen, T.D., Herst, D.E. and Bruek, C.S. (2000) Consequence Associated with Work-Family conflict: A Review and Agenda for Future Research. Journal of Occupational Health Psychology, 2, 273-308. https://doi.org/10.1037/1076-8998.5.2.278

[20] Carlson, D.S., Kacmar, K.M. and Williams, L.J. (2000) Construction and Initial Validation of a Multidimensional Measure of Work-Family Conflict. Journal of Vocational Behavior, 56, 249-276. https://doi.org/10.1006/jvbe.1999.1713

[21] Maslach, C. (1982) Burnout-The Cost of Caring. Prentice-Hall, Englewood Cliffs.

[22] Mobley, W.H., Horner, S.O. and Hollingsworth, A.T. (1978) An Evaluation of Precursors of Hospital Employee Turnover. Journal of Applied Psychology, 63, 408-414. https://doi.org/10.1037/0021-9010.63.4.408

[23] Eisenberger, R. and Adornetto, M. (1986) Generalized Self-Control of Delay and Effort. Journal of Personality \& Social Psychology, 51, 1020-1031. https://doi.org/10.1037/0022-3514.51.5.1020

[24] Gielnik, M.M., Zacher, H. and Wang, M. (2018) Age in the Entrepreneurial Process: The Role of Future Time Perspective and Prior Entrepreneurial Experience. Journal of Applied Psychology, 103, 1067-1085. https://doi.org/10.1037/apl0000322

[25] Vandenberg, R.J. and Lance, C.E. (2000) A Review and Synthesis of the Measurement Invariance Literature: Suggestions, Practices, and Recommendations for Organizational Research. Organizational Research Methods, 3, 4-70. https://doi.org/10.1177/109442810031002

[26] Pan, Z. and Chen, Y.Q. (2012) The Relationship between Work-Family Conflict and Turnover Intention in China. Enterprise Economy, 12, 42.

[27] Frone, M.R., Russell, M. and Cooper, M.L. (1992) Antecedents and Outcomes of Work Family Conflict: Testing a Model of the Work-Family Interfact. Journal of Applied Psychology, 77, 65-78.

[28] Xu, C.J. and Shi, K. (2003) Job Burnout: An Expanding Field of Research. Progress in Psychological Science, 11, 680-685. 